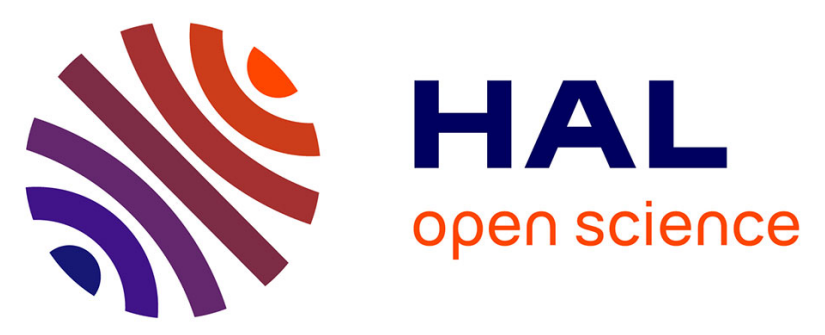

\title{
Low Cross-Reactivity Between Cisplatin and Other Platinum Salts
}

Justine Pasteur, Laure Favier, Corinne Pernot, Mathieu Guerriaud, Charlotte Bernigaud, Côme Lepage, Jean-Louis Jouve, Nicolas Isambert, Evelyne Collet

\section{- To cite this version:}

Justine Pasteur, Laure Favier, Corinne Pernot, Mathieu Guerriaud, Charlotte Bernigaud, et al.. Low Cross-Reactivity Between Cisplatin and Other Platinum Salts. Journal of Allergy and Clinical Immunology: In Practice, 2019, 7, pp.1894 - 1900. 10.1016/j.jaip.2019.01.057 . hal-03487989

\section{HAL Id: hal-03487989 \\ https://hal.science/hal-03487989}

Submitted on 20 Dec 2021

HAL is a multi-disciplinary open access archive for the deposit and dissemination of scientific research documents, whether they are published or not. The documents may come from teaching and research institutions in France or abroad, or from public or private research centers.
L'archive ouverte pluridisciplinaire HAL, est destinée au dépôt et à la diffusion de documents scientifiques de niveau recherche, publiés ou non, émanant des établissements d'enseignement et de recherche français ou étrangers, des laboratoires publics ou privés.

\section{(ㄷ)(1) $\$$}

Distributed under a Creative Commons Attribution - NonCommerciall 4.0 International 


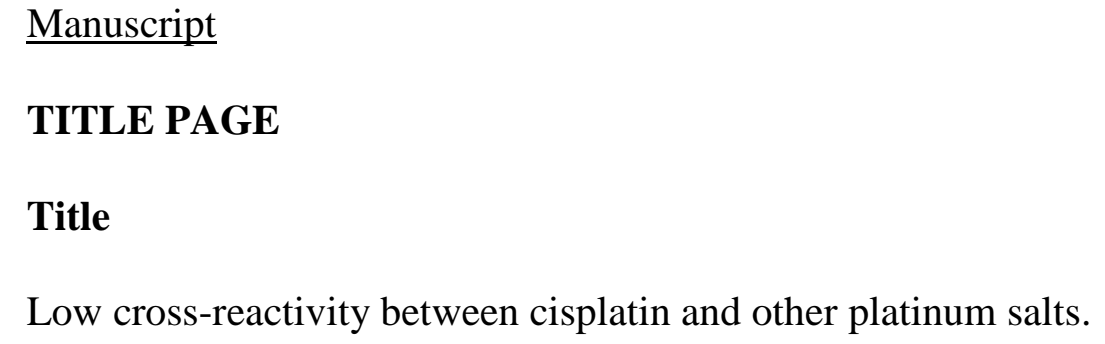

$\underline{\text { Manuscript }}$

\section{TITLE PAGE}

Title

Low cross-reactivity between cisplatin and other platinum salts.

9 Authors

10 Justine Pasteur, M.D. ${ }^{1}$ Laure Favier, M.D. ${ }^{2}$ Corinne Pernot, M.D. ${ }^{3}$ Mathieu Guerriaud, Ph.D. ${ }^{4}$ 11 Charlotte Bernigaud, M.D. ${ }^{1}$ Côme Lepage, M.D. Ph.D. ${ }^{5}$ Jean-Louis Jouve, M.D. ${ }^{5}$ Nicolas 12 Isambert, M.D ${ }^{2}$ Evelyne Collet, M.D. ${ }^{1}$

\section{Affiliations}

$15{ }^{1}$ Dermatology Department, Dijon University Hospital, Dijon, France

$16{ }^{2}$ Oncology Department, Centre Georges-François Leclerc, Dijon, France

$17{ }^{3}$ Pharmacy Department, Dijon University Hospital, Dijon, France

$18{ }^{4}$ University of Burgundy, Dijon, France

$19{ }^{5}$ Gastroenterology Department, Dijon University Hospital, Dijon, France 20

\section{Corresponding author:}

22 Justine Pasteur, M.D.

23 Service de dermatologie, Centre Hospitalier Universitaire, Hôpital François Mitterrand, 2414 rue Paul Gaffarel,

25 BP77908, 21079 Dijon Cedex, France

26 E-mail: justine.pasteur@chu-dijon.fr

27 Phone: +33380293336

28 Fax: +33380293028

29

Conflict of interest: none 
Background: Hypersensitivity reactions to platinum salts (PS) (cisplatin (CI), carboplatin (CA) and oxaliplatin (OX)) can be severe and their incidence is increasing due to their widespread use in cancer treatment.

Objective: To determine the rate of cross-reactivity between platinum salts and whether CI can be administered without prior allergy testing in patients with a history of CA or OX hypersensitivity.

Methods: From September 2002 to April 2016, patients with suspected immediate PS hypersensitivity were tested and cross-reactivity between the three PS was evaluated. We then studied patients who were given cisplatin without desensitization after immediate hypersensitivity to other PS.

Results: A total of 155 patients were included. Skin tests were positive in 97 patients (OX: 51, CA: 43 and CI: 3). Cross-reactivity to CA in OX-allergic patients was $45 \%$ (23/51) (95\% CI: $36 \%$ to $66 \%)$ and cross-reactivity to OX in CA-allergic patients was $37 \%$ (16/43) (95\%CI: $23 \%$ to $53 \%)$. In contrast, cross-reactivity to CI was $0 \%(0 / 51)(95 \% \mathrm{CI}$ : $0 \%$ to $7 \%$ ) in OX-allergic patients and $7 \%$ (3/43) (95\% CI: $2 \%$ to $17 \%$ ) in CA-allergic patients. All these 3 patients had previously been exposed to CI in previous courses of chemotherapy. CI was initiated in 24 patients with proven hypersensitivity to CA or OX and had no hypersensitivity reactions.

Conclusion: Initiating $\mathrm{CI}$ in patients with proven immediate hypersensitivity to $\mathrm{CA}$ or $\mathrm{OX}$ appeared to be safe in our study.

\section{Highlights Box:}

1. What is already known about this topic? The management of immediate hypersensitivity to platinum salts consists in carrying out skin testing and setting up a desensitization protocol. Moreover, cross-reactivity between the three platinum salts is a matter of debate.

2. What does this article add to our knowledge? This study demonstrates that crossreactivity between carboplatin and oxaliplatin $\square$ is very frequent whereas cross-reactivity 64 
653 . How does this study impact current management guidelines? If desensitization can not 66 be proposed and in the accordance with oncologist, cisplatin can be administered safely in 67 patients with a history of carboplatin or oxaliplatin hypersensitivity provided it has never 68 been used before.

69

70 Keywords: Allergy, Immediate hypersensitivity, Platinum salt, Cross-reaction, Skin 71 testing, Chemotherapy, Intradermal test, Anaphylaxis. 
73

74

Abbreviations

75

76 CA Carboplatin

77 CI Cisplatin

78 IDTs Intradermal Tests

79 LDH Lactate dehydrogenase

$80 \quad$ OX Oxaliplatin

$81 \quad$ PS Platinum salt 
Platinum salts (PS) (cisplatin (CI), carboplatin (CA) and oxaliplatin (OX)) are commonly used for the treatment of various cancers such as colorectal, pancreatic and ovarian cancer $^{1-7}$. Immediate hypersensitivity reactions to PS are frequent and estimated at 15 to $20 \%$ in different studies, and can be severe ${ }^{8-14}$. Hypersensitivity reactions to PS are generally observed after a mean of eight infusions ${ }^{13,15}$, although recent studies have shown that they can appear earlier ${ }^{1,2,16}$. Different studies have identified various potential risk factors linked to hypersensitivity: the interval between the end and the resumption of treatment if more than two years ${ }^{17}$, total dose received ${ }^{9,18}$, age ${ }^{19}$, history of drug allergy ${ }^{17}$, HLA DR $3^{20}$, and high serum lactate dehydrogenase (LDH) level at the beginning of chemotherapy $^{21}$.

For diagnosis, skin testing especially intradermal tests (IDTs) are commonly used ${ }^{22-24}$.

Many authors ${ }^{1,22,25}$ demonstrated that IDTs are reliable and have a good negative predictive value.

Currently, the incidence of cross-reactivity between the three PS is unclear, although some studies in a small number of cases have shown that switching to $\mathrm{CI}$ in patients with $\mathrm{CA}$ or OX hypersensitivity was safe in a majority of patients ${ }^{26-28}$. When an allergic reaction occurs during an infusion of PS, treatment is immediately stopped and all three PS are contraindicated until consultation with a specialist and skin allergy testing. Desensitization is considered safe and supported by many publications. If desensitization is not an option, could cisplatin be safely used in patients reactive to oxaliplatin or carboplatin in accordance with oncologist? The aim of this study was to determine the rate of cross-reactivity in patients receiving PS in a teaching hospital in France and whether CI can be administered without prior allergy 
112 We conducted a retrospective, descriptive, single-center study from September 2002 to 113 April 2016 at the Dermatology Department of Dijon University Hospital, France. Patients 114 coming for a dermato-allergology consultation for immediate hypersensitivity reactions to 115 PS were included. An immediate reaction to PS was defined as a reaction that occurs 116 during the infusion or within 1 hour after the infusion of one of the three PS (CA, OX or 117 CI). Skin tests were performed after a minimum of 4-6 weeks after resolution of the hypersensitivity reaction. Indeed, false negative skin testing is possible if it is too early after the hypersensitivity reaction probably due to a period of "anergy" after a systemic reaction. $^{25,29}$

Intradermal tests (IDTs) were performed by using a sterile solution of each PS (active product and excipients): Cisplatine Accord ${ }^{\circledR}$ (cisplatin, injectable form, 100mg/100ml; Accord Healthcare France), Carboplatine Hospira ${ }^{\circledR}$ (carboplatin, injectable form, 450mg/45ml; Hospira, France) and Oxaliplatine Hospira ${ }^{\circledR}$ (oxaliplatin, injectable form, $100 \mathrm{mg} / 20 \mathrm{ml}$; Hospira, France) diluted in $0.9 \%$ saline successively according to the following sequence $(1 / 1000,1 / 100$ and 1/10). Dilutions were prepared following a standardized procedure at the Dijon University Hospital Pharmacy Department under laminar flow 2 hours before injection. IDTs were performed on the patients' upper back by injecting $0.02 \mathrm{~mL}$ of sterile dilutions, which produced a $4 \mathrm{~mm}$ to $6 \mathrm{~mm}$ wheal. IDTs were considered positive if the diameter of the wheal measured $3 \mathrm{~mm}$ more than the diameter of the initial one after 20 minutes. All concomitant treatments and/or premedications (corticosteroids, antiemetic agents, other chemotherapy agents) were also tested if suspected, according to the European Society of Contact Dermatitis guidelines for drug skin testing ${ }^{30}$. After the dermatology consultation and IDTs, the oncologist was consulted to choose the most appropriate PS that was negative during the test to be used for the patient. The drug was then initiated at the therapeutic dose and regimen, without desensitization. Any hypersensitivity reactions were assessed.

In addition, clinical data were collected: age of the patient, sex, cancer type, number of courses administered until a reaction occurred and symptoms of the hypersensitivity reaction. Symptoms were graded according to Brown's classification ${ }^{31}$. 


\section{Patients}

During the 14-year study period, 184 patients had investigations for hypersensitivity reactions to PS. Among these patients, 29 were not analysed because they had a delayed rather than immediate reaction. Finally, 155 remaining patients with immediate hypersensitivity were included (see figure 1). Patients' clinical data are summarized in Table I.

\section{Treatments and hypersensitivity reactions}

152

The suspected PS was CA in 64 cases, OX in 87 cases and CI in 4 cases. The median number of courses administered until the reaction occurred was nine (range: 1-37). Eleven patients had already received another treatment with a different PS in the past (CA: 5, OX: 2 and CI: 4). Clinical signs of immediate hypersensitivity to the PS were grade 1 (mild) in $30 \%$ (47/155), grade 2 (moderate) in 62\% (96/155) and grade 3 (severe) in 8\% (12/155) according to Brown's classification ${ }^{31}$. The most common symptoms were cutaneous manifestations in 107 patients (107/155: 69.0\%). These cutaneous signs were urticaria, pruritus, erythema and angioedema. Other manifestations are detailed in Table II. There were six cases of anaphylactic shock, which occurred during the drug infusion. Skin tests

Skin tests were positive to the suspected PS in 97 of the 155 patients (62.6\%) (CI: 3 cases, CA: 43 cases, OX: 51 cases). Tests were thus negative for 58 patients (58/155: 37.4\%) and two hypersensitivities to concomitant treatment were seen: one positive test for epirubicin (Farmorubicine ${ }^{\circledR}$, Pfizer) anthracycline chemotherapy and another for raniditine (Azantac $\AA$, GlaxoSmithKline) an antagonist of histamine receptor type 2 (Figure 1). No incidents occurred during the test procedures. Among patients with positive skin tests, 41 patients were positive to more than one PS. Thirty-eight patients had positive IDTs to CA and OX, two patients had positive IDTs to $\mathrm{CA}$ and CI and only one had positive IDTs to all three PS. Cross-reactivity to CA in OXallergic patients was $45 \%$ (23/51) (95\%CI: $36 \%$ to 66\%) and cross-reactivity to OX in CA-allergic patients was $37 \%$ (16/43) (95\%CI: $23 \%$ to 53\%). In contrast, cross-reactivity to CI was $0 \%(0 / 51)(95 \% \mathrm{CI}$ : $0 \%$ to $7 \%)$ in OX-allergic patients and 7\% (3/43) (95\% CI: $2 \%$ to $17 \%$ ) in CA-allergic patients but those 3 patients had been previously exposed. In 
174 the 38 cases of cross-reactivity between CA and OX, only two patients had received the 175 two PS successively. The results about the different positive skin tests are resumed in 176 Table III.

\section{Drug re-exposure}

178 After skin testing, the oncologists decided to reinfuse PS in 58 patients (30 patients with 179 positive tests and 28 patients with negative tests). The choice of PS was made by the 180 oncologists and the PS was reinfused without any particular precautions and at the 181 recommended dose.

182 Among the 28 with negative tests: 16 patients were re-exposed to the same PS (CA: 6 and 183 OX: 10), and 12 patients to another PS (CA: 1, OX: 2 and CI: 9). No hypersensitivity 184 reactions were notified.

185 Among the 97 patients to which skin tests were positive, 30 patients were re-exposed with 186 another PS: 24 with CI, two with CA and four with OX; and one patient was desensitized 187 with OX. There were no reactions during the administration (Table IV).

188 Al together, 33 patients were given cisplatin. These patients were given between one and 18924 cycles of cisplatin (mean 9 cycles). No patients experienced hypersensitivity reactions. 190 The treatment was stopped for three reasons: renal failure, deterioration of the patient's 191 general health status, or lack of efficacy. 
Hypersensitivity to PS was first described by Hunter et al. in 1945 among employees working in a refinery ${ }^{32}$. Since then, the incidence of hypersensitivity has risen due to the widespread use of PS in many cancers treatments. Skin testing has proven to be helpful in the diagnosis of IgE-mediated hypersensitivity to a platinum salt. ${ }^{22,25,29}$ We present here, a study with a large number of patients tested after immediate hypersensitivity to PS. Our study included 155 patients with the same baseline epidemiological profile as other published studies on hypersensitivity to PS ${ }^{10,26,33,34}$. To date, the incidence of cross-reactivity between the three most widely used PS is not well-established. Some rare previous studies have demonstrated cross-reactivity between PS based on skin tests ${ }^{35,36}$. In a majority of studies about hypersensitivity to PS, skin tests have been performed just with the suspected PS, and cross-reactivity has been not investigated ${ }^{1}$. Brault et al. have found only one case of cross-reactivity between CA and OX in 14 patients with positive IDTs to $\mathrm{PS}^{37}$. All IDTs to CI were negative. In our study, we showed for the first time that cross-reactivity between CA and OX was very frequent: cross-reactivity to CA was $45 \%$ in OX-allergic patients and cross-reactivity to OX was $37 \%$ in CA-allergic patients with only two patients who had received both PS in the past. This finding therefore probably reflects a true cross-reactivity. In contrast, cross-reactivity between CI and OX or CA was rare: $0 \%$ in OX-allergic patients and $7 \%$ in CA-allergic patients. In our study, there were no cases of cross-reactivity between CI and other PS when CI had never been used in previous courses of chemotherapy. To our knowledge, this observation has never been described in the literature. The different chemical structures of the PS could explain this phenomenon (Figure 2). The three molecules are different and have various pharmacological properties: CI is a diaminodichloroplatin, CA is cyclobutane-dicarboxyloplatin, and OX is a diaminohexaneplatin derivative. The first hypothesis suggested by Caiado et al. ${ }^{38}$ was that the central platinum atom was an epitope. They supported her their theory by showing the presence of platinum specific IgE. Our testing results, however, did not confirm this hypothesis. Indeed, the active metabolites do not seem to be involved in cross-reactivity because CI and CA are transformed into the same diaquaplatin after hydrolysis and these two PS were less involved in cross-reactivity in our study. We therefore propose a new hypothesis, 
namely that the nitrogen-platinum-oxygen-carbon-oxygen-carbon chain (N-Pt-O-CO-C), which is present only in $\mathrm{CA}$ and $\mathrm{OX}$ and not in CI, could be the common epitope explaining cross-reactivity.

Moreover, our study showed that there were no hypersensitivity reactions when CI was initiated in patients with hypersensitivity to CA and OX, when CI had never been used before. In the same way, several studies have shown that re-exposure with $\mathrm{CI}$ after OX or CA hypersensitivity is safe ${ }^{3,8,28,36,39-46}$. To date, only Zweizig et al. ${ }^{47}$, Shelbak et al. ${ }^{48}$ and Dizon et al. ${ }^{26}$ have reported hypersensitivity reactions following a switch to CI. There were four cases of patients who received CI after a hypersensitivity reaction to CA and subsequently developed a severe reaction to CI. Analysis of these four cases showed that all of these patients had received CI several years previously for the first treatment of the cancers. Callahan et al. ${ }^{27}$ and Bergamini et al. ${ }^{45}$ also reported eleven cases of hypersensitivity to $\mathrm{CI}$ at re-exposure after a hypersensitivity reaction to $\mathrm{CA}$. In ten cases, the reaction developed after a median of 3 courses of CI. In our opinion, these cases cannot be regarded as a failure of the re-exposure, but as a new hypersensitivity to CI. In our study, no patient re-exposed to CI experienced hypersensitivity reaction. In two cases of the Callahan et al. ${ }^{27}$ and the Ottaiano et al. ${ }^{49}$ studies, patients experienced a reaction to CI during the first infusion of the re-exposure. Unfortunately, we do not have enough information to analyze these hypersensitivity reactions as we do not know if the patient had previously been treated with CI. In 2015, Kolomeyevskaya et al. ${ }^{39}$ proposed the reintroduction of OX in patients with an allergy to CA, without a skin test. Our results go against this strategy because our tests showed a high frequency of cross-reactivity between CA and OX. The results of all these different studies are summarized in Table V. When patients experience a hypersensitivity reaction during PS infusion, treatment should be stopped immediately. The collaboration between allergist and oncologist is essential. After patient's risk stratification, as proposed by Giavina-Bianchi et al. ${ }^{50}$ based on the severity of the initial reaction, the patient's comorbidities and the drug given to the patients, several possibilities can be proposed to the oncologist. If the oncologist wants to continue the same PS, skin testing should be done as soon as possible. If these tests are positive, desensitization is the best option. Indeed several studies have reported that desensitization is a safe and effective method. ${ }^{29,25,37,50}$ However, this approach needs to be used repeatedly before each infusion. If the oncologist wants to change for any reason, the best approach is skin testing with the three PS: OX, CA and CI. If the oncologist chooses 
258 CI, the risk of immediate hypersensitivity reaction seems very low as shown in this study. 259 In our experience, this option can be useful in gynecologic cancer but less so in digestive 260 cancer as the three PS are not equivalent in terms of efficacy and tolerance. If skin testing 261 is negative, a drug provocation test or regular infusion can be proposed based on the risk 262 stratification ${ }^{50}$. As the administration of chemotherapy is far from risk-free, the benefit263 risk ratio must always be evaluated. Moreover, patients should be advised about the risk 264 and closely monitored by experienced medical staff. 


\section{Figure legends}

267 Figure 1. Flowchart of the study. 155 patients had immediate hypersensitivity to PS and were 268 included in the retrospective study.

270 Figure 2. Chemical structure of cisplatin (a), carboplatin (b) and oxaliplatin (c) molecules are 271 presented in this figure. The N-Pt-O-CO-C chain present in both carboplatin and oxaliplatin is 272 highlighted in the blue diagram.

273

274 


\section{Acknowlegdements}

277 We thank the nurses for consultations and the secretaries of the Dermatology Department, 278 Dijon University Hospital, Dijon, France, the staff of the archives of Centre Georges-François 279 Leclerc, Dijon, France and Mr Philip Bastable, Research Unit at Dijon University Hospital. 280 


\section{References}

283 1. Wong JT, Ling M, Patil S, Banerji A, Long A. Oxaliplatin hypersensitivity: evaluation, 284 implications of skin testing, and desensitization. J Allergy Clin Immunol Pract. 2014 285 Feb;2(1):40-5.

2. Park H, Lee J, Kim S, Kim S, Park K, Lee C, et al. A New Practical Desensitization

3. Shukunami K, Kurokawa T, Kubo M, Kaneshima M, Kamitani N, Kotsuji F. 290 Protocol for Oxaliplatin-Induced Immediate Hypersensitivity Reactions: A Necessary and Useful Approach. J Investig Allergol Clin Immunol. 2016 Jun 20;26(3):168-76.

6. Raymond E, Faivre S, Chaney S, Woynarowski J, Cvitkovic E. Cellular and molecular pharmacology of oxaliplatin. Mol Cancer Ther. 2002 Jan;1(3):227-35.

7. Kelland L. The resurgence of platinum-based cancer chemotherapy. Nat Rev Cancer. 2007 Aug;7(8):573-84.

8. Polyzos A, Tsavaris N, Kosmas C, Arnaouti T, Kalahanis N, Tsigris C, et al. Hypersensitivity reactions to carboplatin administration are common but not always severe: a 10-year experience. Oncology. 2001;61(2):129-33.

9. Navo M, Kunthur A, Badell ML, Coffer LW, Markman M, Brown J, et al. Evaluation of the incidence of carboplatin hypersensitivity reactions in cancer patients. Gynecol Oncol. 2006 Nov;103(2):608-13.

10. Maindrault-Goebel F, André T, Tournigand C, Louvet C, Perez-Staub N, Zeghib N, et

311 11. Lee M-Y, Yang M-H, Liu J-H, Yen C-C, Lin P-C, Teng H-W, et al. Severe anaphylactic 312 reactions in patients receiving oxaliplatin therapy: a rare but potentially fatal 
complication. Support Care Cancer Off J Multinatl Assoc Support Care Cancer. 2007 Jan;15(1):89-93.

12. Wang J-H. Oxaliplatin-induced severe anaphylactic reactions in metastatic colorectal cancer: Case series analysis. World J Gastroenterol. 2012;18(38):5427.

13. Sliesoraitis S, Chikhale PJ. Carboplatin hypersensitivity. Int J Gynecol Cancer Off J Int Gynecol Cancer Soc. 2005 Feb;15(1):13-8.

14. Makrilia N, Syrigou E, Kaklamanos I, Manolopoulos L, Saif MW. Hypersensitivity Reactions Associated with Platinum Antineoplastic Agents: A Systematic Review. MetBased Drugs. 2010;2010:1-11.

15. Markman M, Kennedy A, Webster K, Elson P, Peterson G, Kulp B, et al. Clinical features of hypersensitivity reactions to carboplatin. J Clin Oncol Off J Am Soc Clin Oncol. 1999 Apr;17(4):1141.

16. Parel M, Ranchon F, Nosbaum A, You B, Vantard N, Schwiertz V, et al. Hypersensitivity to oxaliplatin: clinical features and risk factors. BMC Pharmacol Toxicol. 2014;15(1):1.

17. Schwartz JR, Bandera C, Bradley A, Brard L, Legare R, Granai CO, et al. Does the

19. Joly F, Ray-Coquard I, Fabbro M, Donoghoe M, Boman K, Sugimoto A, et al.

21. Seki K, Tsuduki Y, Ioroi T, Yamane M, Yamauchi H, Shiraishi Y, et al. Serum Lactate platinum-free interval predict the incidence or severity of hypersensitivity reactions to carboplatin? The experience from Women and Infants' Hospital. Gynecol Oncol. 2007 Apr;105(1):81-3.

18. Sugimoto H, Iwamoto T, Murashima Y, Tabata T, Sagawa N, Okuda M. Risk factors contributing to the development of carboplatin-related delayed hypersensitivity reactions in Japanese patients with gynecologic cancers. Cancer Chemother Pharmacol. 2011 Feb;67(2):415-9.

Decreased hypersensitivity reactions with carboplatin-pegylated liposomal doxorubicin compared to carboplatin-paclitaxel combination: analysis from the GCIG CALYPSO relapsing ovarian cancer trial. Gynecol Oncol. 2011 Aug;122(2):226-32.

20. Newman Taylor AJ, Cullinan P, Lympany PA, Harris JM, Dowdeswell RJ, du Bois RM. Interaction of HLA phenotype and exposure intensity in sensitization to complex platinum salts. Am J Respir Crit Care Med. 1999 Aug;160(2):435-8.

Dehydrogenase Levels as a Predictive Marker of Oxaliplatin-Induced Hypersensitivity Reactions in Japanese Patients with Advanced Colorectal Cancer. Int J Med Sci. 2014;11(6):641-5. 
22. Leguy-Seguin V, Jolimoy G, Coudert B, Pernot C, Dalac S, Vabres P, et al. Diagnostic and predictive value of skin testing in platinum salt hypersensitivity. J Allergy Clin Immunol. 2007 Mar;119(3):726-30.

23. Markman M, Zanotti K, Peterson G, Kulp B, Webster K, Belinson J. Expanded experience with an intradermal skin test to predict for the presence or absence of carboplatin hypersensitivity. J Clin Oncol Off J Am Soc Clin Oncol. 2003 Dec 15;21(24):4611-4.

24. Zanotti KM, Rybicki LA, Kennedy AW, Belinson JL, Webster KD, Kulp B, et al. Carboplatin skin testing: a skin-testing protocol for predicting hypersensitivity to carboplatin chemotherapy. J Clin Oncol Off J Am Soc Clin Oncol. 2001 Jun $15 ; 19(12): 3126-9$.

25. Lax T, Long A, Banerji A. Skin Testing in the Evaluation and Management of Carboplatin-Related Hypersensitivity Reactions. J Allergy Clin Immunol Pract. 2015 Dec;3(6):856-62.

26. Dizon DS, Sabbatini PJ, Aghajanian C, Hensley ML, Spriggs DR. Analysis of patients with epithelial ovarian cancer or fallopian tube carcinoma retreated with cisplatin after the development of a carboplatin allergy. Gynecol Oncol. 2002 Mar;84(3):378-82.

27. Callahan MB, Lachance JA, Stone RL, Kelsey J, Rice LW, Jazaeri AA. Use of cisplatin without desensitization after carboplatin hypersensitivity reaction in epithelial ovarian and primary peritoneal cancer. Am J Obstet Gynecol. 2007 Aug;197(2):199.e1-4; discussion 199.e4-5.

28. Elligers KT, Davies M, Sanchis D, Ferencz T, Saif MW. Rechallenge with cisplatin in a patient with pancreatic cancer who developed a hypersensitivity reaction to oxaliplatin. Is skin test useful in this setting. JOP J Pancreas Online. 2008;9(2):197-202.

29. Castells MC, Tennant NM, Sloane DE, Hsu FI, Barrett NA, Hong DI, et al. Hypersensitivity reactions to chemotherapy: outcomes and safety of rapid desensitization in 413 cases. J Allergy Clin Immunol. 2008 Sep;122(3):574-80.

30. Barbaud A, Gonçalo M, Bruynzeel D, Bircher A. Guidelines for performing skin tests withdrugs in the investigation of cutaneous adverse drug reactions. Contact Dermatitis. 2001 Dec 1;45(6):321-8.

31. Brown SGA. Clinical features and severity grading of anaphylaxis. J Allergy Clin Immunol. 2004 Aug;114(2):371-6.

32. Hunter D, Milton R, Perry KM. Asthma caused by the complex salts of platinum. Br J Ind Med. 1945;2(2):92. 
33. Greene DP, Ferriss JS, Jazaeri AA. Cisplatin administration following carboplatin desensitization failure in primary peritoneal cancer: a brief report. Cancer Chemother Pharmacol. 2010 Jul;66(2):265-7.

34. Li Q, Cohn D, Waller A, Backes F, Copeland L, Fowler J, et al. Outpatient rapid 4-step desensitization for gynecologic oncology patients with mild to low-risk, moderate hypersensitivity reactions to carboplatin/cisplatin. Gynecol Oncol. 2014 Oct;135(1):904.

35. Caiado J, Castells M. Presentation and Diagnosis of Hypersensitivity to Platinum Drugs. Curr Allergy Asthma Rep [Internet]. 2015 Apr [cited 2016 Apr 18];15(4). Available from: http://link.springer.com/10.1007/s11882-015-0515-3

36. Enrique E, Malek T, Castelló JV, De Mateo JA. Usefulness of skin testing with platinum salts to demonstrate lack of cross-reactivity between carboplatin and cisplatin. Ann Allergy Asthma Immunol. 2008;100(1):86.

37. Brault F, Waton J, Poreaux C, Schmutz J-L, Barbaud A. [Hypersensitivity to platinum salts and taxanes: The value of skin tests and tolerance induction procedures]. Ann Dermatol Venereol. 2017 Nov;144(11):685-95.

38. Caiado J, Venemalm L, Pereira-Santos MC, Costa L, Barbosa MP, Castells M. Carboplatin-, oxaliplatin-, and cisplatin-specific IgE: cross-reactivity and value in the diagnosis of carboplatin and oxaliplatin allergy. J Allergy Clin Immunol Pract. 2013 Oct;1(5):494-500.

39. Kolomeyevskaya NV, Lele SB, Miller A, Riebandt GC, Blum BL, Odunsi KO, et al. Oxaliplatin is a safe alternative option for patients with recurrent gynecologic cancers after hypersensitivity reaction to Carboplatin. Int J Gynecol Cancer Off J Int Gynecol Cancer Soc. 2015 Jan;25(1):42-8.

40. Syrigou E, Makrilia N, Vassias A, Nikolaidis I, Xyla V, Manolopoulos L, et al. Administration of cisplatin in three patients with carboplatin hypersensitivity: is skin testing useful? Anticancer Drugs. 2010 Mar;21(3):333-8.

41. Kandel MJ, Loehr A, Harter P, Traut A, Gnauert K, du Bois A. Cisplatinum rechallenge in relapsed ovarian cancer patients with platinum reinduction therapy and carboplatin hypersensitivity. Int J Gynecol Cancer Off J Int Gynecol Cancer Soc. 2005 Oct; 15(5):780-4.

42. Libra M, Sorio R, Buonadonna A, Berretta M, Stefanovski P, Toffoli G, et al. Cisplatin may be a valid alternative approach in ovarian carcinoma with carboplatin hypersensitivity. Report of three cases. Tumori. 2003 Jun;89(3):311-3. 
43. Porzio G, Marchetti P, Paris I, Narducci F, Ricevuto E, Ficorella C. Hypersensitivity reaction to carboplatin: successful resolution by replacement with cisplatin. Eur $\mathbf{J}$ Gynaecol Oncol. 2002;23(4):335-6.

44. Weidmann B, Mülleneisen N, Bojko P, Niederle N. Hypersensitivity reactions to carboplatin. Report of two patients, review of the literature, and discussion of diagnostic procedures and management. Cancer. 1994 Apr 15;73(8):2218-22.

45. Bergamini A, Pisano C, Di Napoli M, Arenare L, Della Pepa C, Tambaro R, et al. Cisplatin can be safely administered to ovarian cancer patients with hypersensitivity to carboplatin. Gynecol Oncol. 2017 Jan;144(1):72-6.

46. Polyzos A, Tsavaris N, Kosmas C

C, Arnaouti T, Kalahanis N, Tsigris C, et al. Hypersensitivity reactions to carboplatin administration are common but not always severe: a 10-year experience. Oncology. 2001;61(2):129-33.

47. Zweizig S, Roman LD, Muderspach LI. Death from anaphylaxis to cisplatin: a case report. Gynecol Oncol. 1994 Apr;53(1):121-2.

48. Shlebak AA, Clark PI, Green JA. Hypersensitivity and cross-reactivity to cisplatin and analogues. Cancer Chemother Pharmacol. 1995;35(4):349-51.

49. Ottaiano A, Tambaro R, Greggi S, Prato R, Di Maio M, Esposito G, et al. Safety of cisplatin after severe hypersensitivity reactions to carboplatin in patients with recurrent ovarian carcinoma. Anticancer Res. 2003 Aug;23(4):3465-8.

50. Giavina-Bianchi P, Patil SU, Banerji A. Immediate Hypersensitivity Reaction to Chemotherapeutic Agents. J Allergy Clin Immunol Pract. 2017 Jun;5(3):593-9. 
Patients tested for PS at Dijon University Hospital from September 2002 to April 2016

$$
\mathrm{n}=184
$$

Exclusion : $n=29$ (delayed reactions)

Immediate hypersensitivity reactions

$$
\mathrm{n}=155
$$

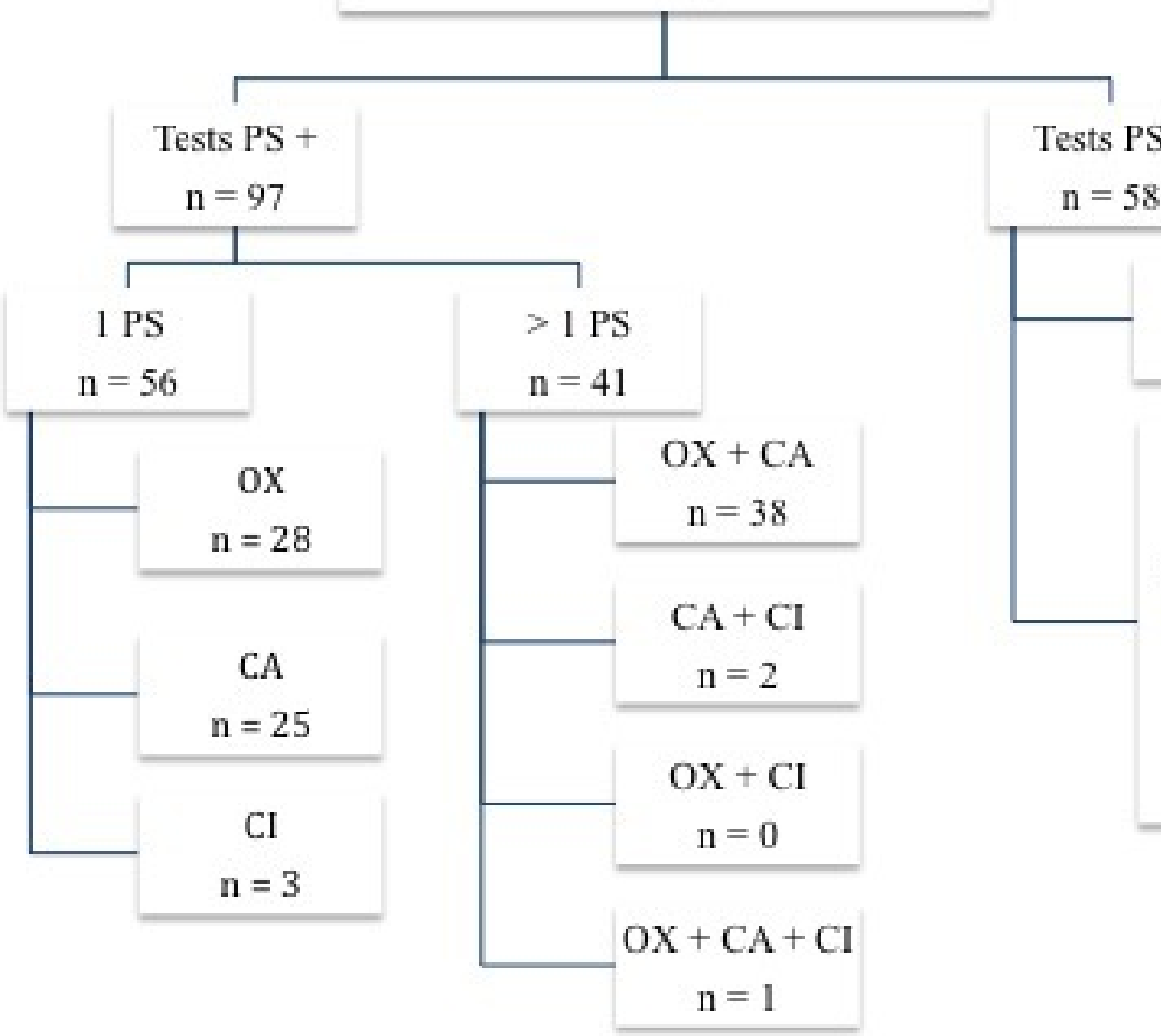

for all

$\mathrm{n}=56$

Concomittant treatment hypersensitivity

$$
\mathrm{n}=2
$$

Epirubicin Ranitidine 


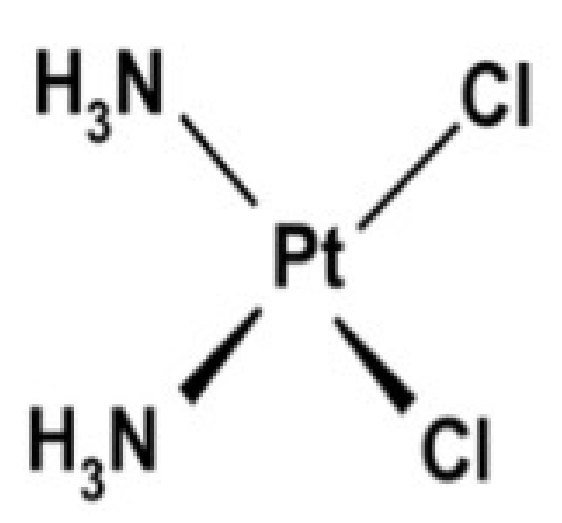

a. cisplatin

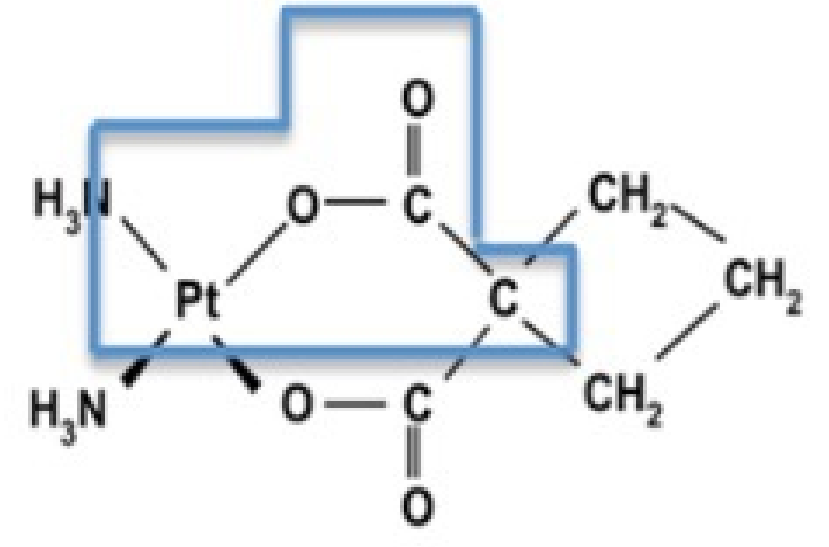

b. carboplatin

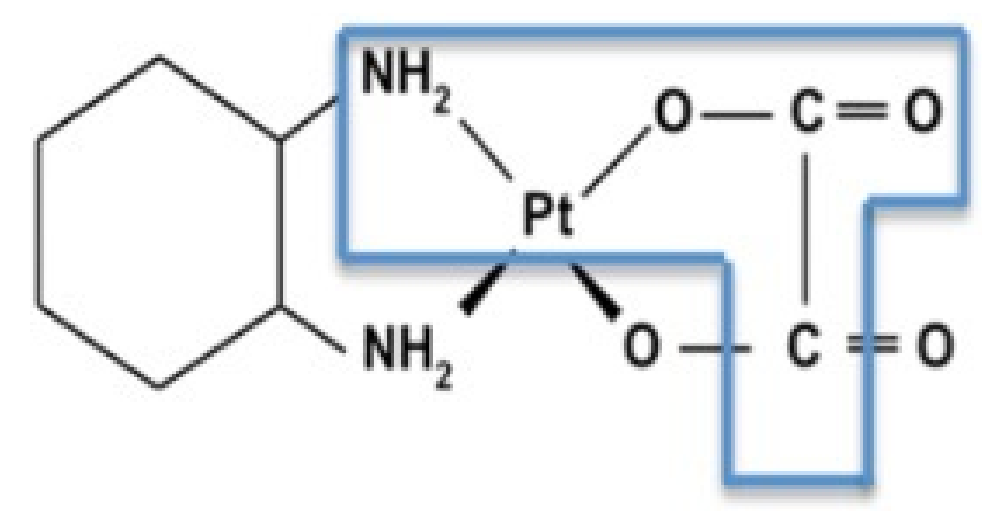

c. oxaliplatin

N-Pt-O-CO-C chain 
Table I. Baseline demographic characteristics of patients $(n=155)$

\begin{tabular}{lll}
\hline Age, years & $27-82$ \\
\hline Range & 60.8 \\
Mean & 60 \\
Median & \multicolumn{2}{l}{} \\
\hline Gender, no (\%) & 103 & $(66.4)$ \\
\hline Female & 52 & $(33.6)$ \\
Male & 1.9 & \\
Sex ratio & \multicolumn{2}{l}{} \\
\hline Tumor type, no (\%) & 55 & $(35.5)$ \\
Colorectal & 52 & $(33.6)$ \\
Ovarian & 14 & $(9)$ \\
Pancreatic & 6 & $(3.8)$ \\
Cholangiocarcinoma & 6 & $(3.8)$ \\
Gastric & 6 & $(3.8)$ \\
Pulmonary & 4 & $(2.6)$ \\
Breast & 4 & $(2.6)$ \\
Endometrial & 3 & $(1.8)$ \\
Esophageal & 1 & $(0.7)$ \\
Cervix & 1 & $(0.7)$ \\
Fallopian tube & 1 & $(0.7)$ \\
Peritoneal & 1 & $(0.7)$ \\
Pharynx & 1 & $(0.7)$ \\
Prostate & &
\end{tabular}




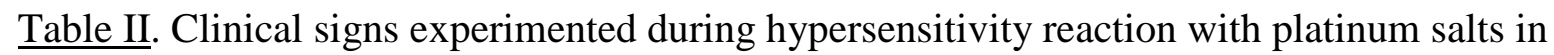
the 155 patients.

\section{Clinical signs}

Patients, no (\%)

Cutaneous (erythema, pruritus, urticaria, angioedema)

$107(69)$

Cardiovascular (chest tightness, Tachycardia, blood pressure alterations)

Pulmonary (dyspnea, bronchospasm, desaturation)

$47(30)$

Gastro-intestinal (nausea, vomiting, diarrhea) $18(12)$

Neurological (paresthesia, malaise, vertigo) 


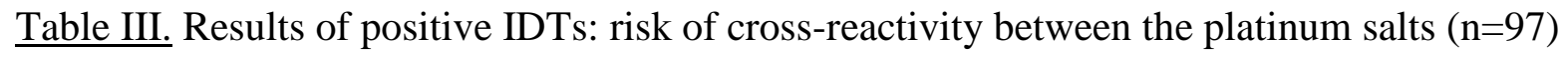

\begin{tabular}{ccc}
\hline Suspected PS with positive IDTs & IDTs results & Patients, no. (\%) \\
\hline Oxaliplatin $\mathbf{n = 5 1}$ & OX alone & $28(55)$ \\
& OX + CA & $23(45)$ \\
& OX + CI & $0(0)$ \\
& OX + CA + CI & $0(0)$ \\
\hline Carboplatin $\mathbf{n = 4 3}$ & CA & $25(58)$ \\
& CA + OX & $15(35)$ \\
& CA + CI & $2(5)$ \\
& CA + CI +OX & $1(2)$ \\
\hline Cisplatin $\mathbf{n = 3}$ & CI alone & $3(100)$ \\
& CI + CA & $0(0)$ \\
& CI + OX & $0(0)$ \\
\hline
\end{tabular}

IDTs, Intradermal tests

CA, Carboplatin

OX, Oxaliplatin

CI, Cisplatin 


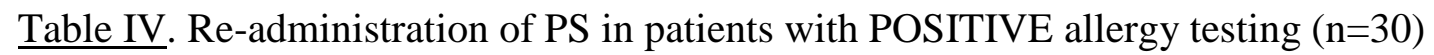

\begin{tabular}{|c|c|c|c|c|c|}
\hline \multicolumn{2}{|l|}{ Suspected PS } & \multirow{2}{*}{$\begin{array}{l}\begin{array}{l}\text { Results of } \\
\text { skin tests }\end{array} \\
\mathrm{CI}+\end{array}$} & \multicolumn{2}{|l|}{ PS administered } & \multirow{2}{*}{$\begin{array}{l}\begin{array}{l}\text { Hypersensitivity } \\
\text { reaction }\end{array} \\
\text { NO }\end{array}$} \\
\hline Cisplatin & $\mathrm{n}=1$ & & Carboplatin & $\mathrm{n}=1$ & \\
\hline \multirow[t]{3}{*}{ Carboplatin } & $\mathrm{n}=9$ & $\mathrm{CA}+$ & Cisplatin & $\mathrm{n}=6$ & $\mathrm{NO}$ \\
\hline & & & Oxaliplatin & $\mathrm{n}=3$ & $\mathrm{NO}$ \\
\hline & $\mathrm{n}=8$ & $\mathrm{CA}+, \mathrm{OX}+$ & Cisplatin & $\mathrm{n}=8$ & $\mathrm{NO}$ \\
\hline \multirow[t]{4}{*}{ Oxaliplatin } & $\mathrm{n}=7$ & $\mathrm{OX}+$ & Cisplatin & $\mathrm{n}=6$ & $\mathrm{NO}$ \\
\hline & & & Carboplatin & $\mathrm{n}=1$ & NO \\
\hline & $\mathrm{n}=5$ & $\mathrm{OX}+, \mathrm{CA}+$ & Cisplatin & $\mathrm{n}=4$ & $\mathrm{NO}$ \\
\hline & & & $\begin{array}{l}\text { Oxaliplatin } \\
\text { (desensitization) }\end{array}$ & $\mathrm{n}=1$ & \\
\hline
\end{tabular}

PS, platinum salts; CA, carboplatin; OX, oxaliplatin; CI, cisplatin; + means positive skin test 


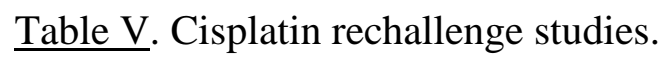

\begin{tabular}{|c|c|c|c|c|c|c|c|}
\hline Study & & Type of cancer & $\mathbf{n}$ & PS suspected & Successful, no (\%) & Allergy, no (\%) & Skin testing \\
\hline Our study & 2016 & all types & 33 & $\begin{array}{l}\text { Carboplatin } \\
\text { Oxaliplatin }\end{array}$ & $33(100)$ & 0 & Yes \\
\hline Bergamini et al. & 2016 & gynecological & 38 & Carboplatin & $33(86.8)$ & $5(13.2)$ & No \\
\hline $\begin{array}{l}\text { Kolomeyevskaya et } \\
\text { al. }\end{array}$ & 2015 & gynecological & 19 & Carboplatin & $19(100)$ & 0 & No \\
\hline Syrigou et al. & 2010 & $\begin{array}{l}\text { ovarian, } \\
\text { pulmonary }\end{array}$ & 3 & Carboplatin & $3(100)$ & 0 & Yes \\
\hline Greene et al. & 2009 & gynecological & 1 & Carboplatin & $1 \quad(100)$ & 0 & No \\
\hline Enrique et al. & 2008 & ovarian & 2 & Carboplatin & $2(100)$ & 0 & Yes \\
\hline Elligers et al. & 2008 & pancreatic & 1 & Oxaliplatin & $1 \quad(100)$ & 0 & Yes \\
\hline Callahan et al. & 2007 & gynecological & 24 & Carboplatin & $18(75)$ & $6(25)$ & No \\
\hline Kandel et al. & 2005 & gynecological & 5 & Carboplatin & $5(100)$ & 0 & No \\
\hline Libra et al. & 2003 & ovarian & 3 & Carboplatin & $3(100)$ & 0 & NA \\
\hline Ottaiano et al. & 2003 & ovarian & 10 & Carboplatin & $9(90)$ & $1(10)$ & NA \\
\hline Dizon et al. & 2002 & ovarian & 7 & Carboplatin & $5 \quad(71.4)$ & $1(14.3)$ & No \\
\hline Porzio et al. & 2002 & ovarian & 1 & Carboplatin & $1 \quad(100)$ & 0 & Yes \\
\hline Polygos et al. & 2001 & ovarian & 4 & Carboplatin & $4 \quad(100)$ & 0 & No \\
\hline Shukunami et al. & 1999 & ovarian & 1 & Carboplatin & $1 \quad(100)$ & 0 & NA \\
\hline Shelbak et al. & 1995 & ovarian & 1 & Carboplatin & 0 & $1(100)$ & No \\
\hline Weidmann et al. & 1994 & ovarian, pancreatic & 2 & Carboplatin & $2(100)$ & 0 & No \\
\hline Zweizig et al. & 1994 & ovarian & 1 & Carboplatin & 0 & 0 & No \\
\hline
\end{tabular}

NA, Not available; PS, Platinum Salt 